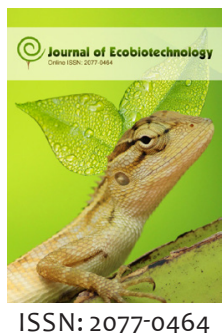

ISSN: 2077-0464

Received: March 19, 2021 Revised: December 18, 2021 Accepted: December 22, 2021 Published: December 27, 2021

*Corresponding author: Obadia Kyetuza Bishoge E-mail: obishoge@yahoo. co.uk

\section{The nexus of energy resources and the environment}

\author{
Obadia Kyetuza Bishoge ${ }^{1,2 *}$ \\ ${ }^{1}$ Pan African University Life and Earth Sciences Institute (Including Health and Agriculture), Ibadan, Nigeria, \\ ${ }^{2}$ National Institute for Medical Research, P. O. Box 9653, Dar es Salaam, Tanzania
}

\begin{abstract}
Currently, every country is striving to realize development for its people. Thus, to achieve this there is a need for ensuring access to reliable energy at all levels. The world is currently relying on the use of non-renewable energy such as fuels, and coal. However, these sources are not environmental friendly. Thus, renewable energy sources such as hydropower, solar energy, geothermal, and biofuels must be emphasized to replace the use of non-renewable energies. People need to understand well the relationship between energy resources and the environment. This paper, therefore, aims at providing the nexus of energy resources and the environment. To achieve this, the author has explained well the concept of energy and energy resources; energy uses and energy efficiency and energy security. Moreover, the author has discussed the impact of energy resources on the environment. Finally, energy savings and practices to best energy use; use of technologies to reduce the pollutant emissions in the atmosphere; and investment in renewable technologies are needed for attaining sustainable energy and environment.
\end{abstract}

KEYWORDS: Energy efficiency and security; Energy resources; Environment; Nonrenewable energy; Renewable energy

\section{INTRODUCTION}

Access to energy is a key pillar for socio-economic and political development. Ensuring everyone has sufficient energy access is an ongoing and pressing challenge for global development (The World Bank, 2018). Energy is the capacity to do work and is required for life processes. An energy resource is something that can produce heat, power life, move objects, or produce electricity. Matter that stores energy is called fuel. Human energy consumption has grown steadily throughout human history.

Early humans had modest energy requirements, mostly food and fuel for fires to cook and keep warm. In today's society, humans consume as much as 110 times as much energy per person as early humans (Nelson, 2015). Most of the energy used today comes from fossil fuels. But fossils fuels have a disadvantage in that they are non-renewable on a human time scale, and cause other potentially harmful effects on the environment. Historical and current energy systems are dominated by fossil fuels (coal, oil and gas) which produce carbon dioxide $\left(\mathrm{CO}_{2}\right)$ and other greenhouse gases- the fundamental driver of global climate change. If we are to meet our global climate targets and avoid dangerous climate change, the world needs a significant and concerted transition in its energy sources. Balancing the challenge between development and environment, therefore, provides us with an ultimate goal of ensuring everyone has access to enough sustainable energy to maintain a high standard of living

Energy can be simply described as a dynamic indicator that shows the development level of the countries. The key pillar for human wellbeing, economic development, and poverty alleviation is access to energy. Since the earliest human civilization up to modern society energy has been the primary driver for economic growth. This is the main reason why humankind is continuously searching for ample sources of energy. Hence, it is a pressing challenge in the global community to ensure that everyone in each nation of the world has access to energy sources.

The energy we use to support the whole range of human activities comes from a variety of sources such as fossil fuels (coal, oil, and natural gas) currently provide the majority of our energy on a global basis, supplying about $81 \%$ of the energy we use (Alley et al., 2020), as indicated in Figure 1.

\section{ENERGY RESOURCES}

\section{Non-renewable energy resources}

Non-renewable energy refers to the energy resources that have been replenished for a long time. Most of the energy we use

Copyright: (-) The authors. This article is open access and licensed under the terms of the Creative Commons Attribution License (http://creativecommons.org/licenses/by/4.0/) which permits unrestricted, use, distribution and reproduction in any medium, or format for any purpose, even commercially provided the work is properly cited. Attribution - You must give appropriate credit, provide a link to the license, and indicate if changes were made. 


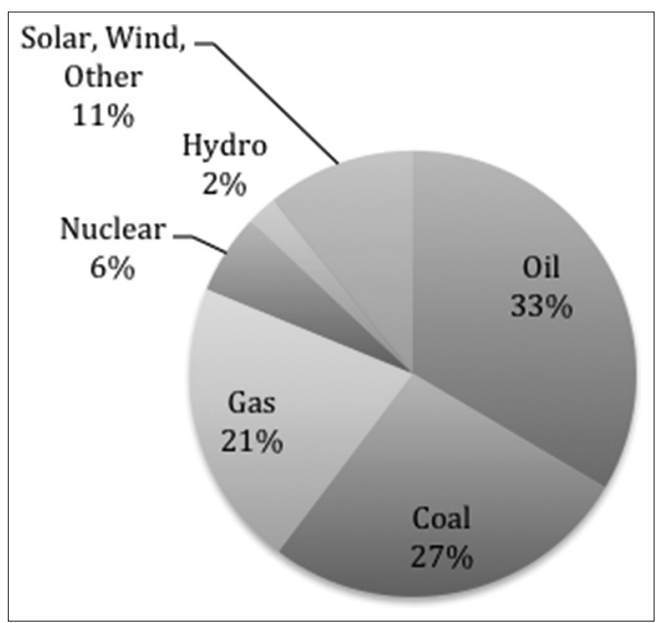

Figure 1: The current contributions to our global energy from different sources show that fossil fuels account for $81 \%$ of our energy (Alley et al., 2020)

comes from fossil fuels such as coal, natural gas and petroleum. Uranium is another nonrenewable source, but it is not a fossil fuel. Uranium is converted to fuel and used in nuclear power plants. Once these natural resources are used up, they are gone forever. The process of gathering these fuels can be harmful to the environment from which they come. Fossil fuels are put through a process called combustion to produce energy. Combustion releases pollution such as carbon monoxide and sulfur dioxide, which may contribute to acid rain and global warming.

\section{Renewable Energy Resources}

Renewable energy refers to the energy resources that have been replenished naturally for a short time. Renewable sources of energy can be used over and over again. Renewable resources include solar energy, wind, geothermal, biomass and hydropower. They generate much less pollution, both in gathering and production than nonrenewable sources (Xavier et al., 2017).

- Solar energy comes from the sun. Some people use solar panels on their homes to convert sunlight into electricity.

- Wind turbines, which look like giant windmills, generate electricity.

- Geothermal energy comes from the Earth's crust. Engineers extract steam or very hot water from the Earth's crust and use the steam to generate electricity.

- Biomass includes natural products such as wood, manure and corn. These materials are burned and used for heat.

- Dams and rivers generate hydropower. When water flows through a dam it activates a turbine, which runs an electric generator.

\section{PRIMARY AND SECONDARY ENERGY}

Primary energy is an energy form found in nature that has not been subjected to any human engineered conversion process (Sauar, 2018). It is the energy contained in raw fuels, and other forms of energy received as input to a system. Primary energy can be non-renewable or renewable.
Secondary energy refers to the more convenient forms of energy which are transformed from other, primary, energy sources through energy conversion processes, as indicated in Figure 2.

\section{ENERGY CONSUMPTION}

Energy consumption is also known as energy use. Think on the everyday human life actions such as listening to music on the radio and watching videos on the televisions; lightning homes, calling and receiving calls on the mobile phones; taking shower with warmed water by water heaters; travelling from one place to another by bus, motorcycles, train or aeroplanes; and cooking and warming foods. The energy is used to drive these actions. This indicates that our daily lives depend on energy. Globally, the water-food-energy nexus is a central tool for sustainable development (Simpson \& Jewitt, 2019). Currently, the need for all three is gradually increasing due to rapid population and economic growth and urbanization and changing lifestyles such as diets (D'Odorico et al., 2018).

The use of energy varies considerably across high and lowincome countries; and countries with low and high populations. Currently, energy consumption is highest in developed countries and high population countries. This is due to a high concentration of industry, high levels of car ownership and high domestic usage from homes filled with energy appliances. For instance, in the USA and Canada, energy consumption per person (a reliable indicator of a country's level of economic development) is double to that of Europe and more than 800 times that of developing countries. Also, the increase in population growth leads to an increase in energy demand. Moreover, according to the US Energy Information Administration (EIA, 2013), it is believed that developing countries including China and India will account for 65\% of the world's energy consumption by 2040. The reason behind this projection is due to increasing population and economic growth pace in these countries.

Energy consumption has been increasing globally. For instance, global energy consumption grew rapidly at a rate of $2.9 \%$, led by natural gas and renewable energies in 2018 (BP, 2019). Increased energy consumption has been influenced by the increase in energy demand in the world. The global energy demand is initiated by the fast growth of industrialization and population by which more fossils fuels such as oil, coal, and natural gas are depleted to meet this demand. Energy consumption also varies from one nation to another (Zaharia et al., 2019). For instance, China is leading accounting for $23.6 \%$, followed by the United States (16.6\%), European Union (14\%), Russia (5.2\%), Japan (3.3\%), Africa (3.3\%) and Canada (2.5\%) (BP, 2019), as presented in Table 1.

\section{Types of energy users}

According to the US Department of Energy (The NEED Project, 2018), the major energy-consuming sectors are industrial, transportation (especially public transit systems), residential, and commercial. 
Table 1: Global energy consumption by 2018

\begin{tabular}{lcc}
\hline No. Region/country & Bcm (2018) & $\begin{array}{c}\text { Global share } \\
\text { in \% }\end{array}$ \\
\hline 1. Asia Pacific & $5,985.8$ & 43.2 \\
China* & $3,273.5$ & 23.6 \\
2. North America & 2,832 & 20.4 \\
USA* & 2300.6 & 16.6 \\
3. Europe & $2,050.7$ & 14.8 \\
Germany* & 323.9 & 2.3 \\
4. Commonwealth of Independent States & 930.5 & 6.7 \\
Russia* & 720.7 & 5.2 \\
5. Middle East & 902.3 & 6.5 \\
Iran* & 285.7 & 2.1 \\
6. South and Central America & 702 & 5.1 \\
Brazil* & 292.6 & 2.1 \\
7. Africa & 461.5 & 3.3 \\
South Africa* & 121.5 & 0.9 \\
* Leading country in each region & & \\
Source: BP (2019) & &
\end{tabular}

Industrial uses of energy

Energy allows industries to extract resources and produce goods. The industry is business as it is for commerce but industrial means producing goods, usually from raw materials, and commerce commercial means selling and buying goods (Hanania et al., 2020a). These terms are interdependent. The industrial sector is the largest energy user, accounting for about $54 \%$ of the world's total energy (EIA, 2016) and is expected to grow by $1.5 \%$ globally per annum by 2035 (Jordan, 2014). Energy is consumed in activities such as refining, mining, manufacturing, agriculture, and construction. The industrial sector is categorized into three groups, as shown in Table 2: - (i) energy-intensive manufacturing, (ii) non-energy intensive manufacturing, and (iii) nonmanufacturing. Energy used in the industrial sector differs across regions and countries, depending on the levels and integration of economic and technological development (EIA, 2016).

\section{Transportation uses of energy}

The transportation sector is $100 \%$ dependent on energy. The transport sector includes all vehicles from personal cars to trucks, buses and motorcycles. It also includes aircraft, trains, ship and pipelines. Transportation energy-consuming aspects include the production, operation, and decommissioning of all vehicles and infrastructure (Hanania et al., 2020b). The transport sector consumes over $70 \%$ of the global total used petroleum. Road transport consumes approximately $70 \%$ of the total energy used in the global transport system. The overall quest for energy efficiency depends on the transportation sector (National Research Council, 2010). Currently, different countries are innovating in various ways such as the introduction of more fuel-efficient vehicles and the development of alternative sources of energy for the transport system to save energy and reduce carbon dioxide emissions. Energy efficiency in the transportation sector offers huge potential for reducing energy demand. The reduction of traffic volume is a key facet of energy efficiency in the transportation sector (Kutani, 2017). Other facets include (i) avoiding increased transport activity
Table 2: World industrial sector: major groupings and representative industries (EIA, 2016)

\begin{tabular}{|c|c|c|}
\hline No. & Industry grouping & Representative industries \\
\hline \multirow[t]{8}{*}{1.} & $\begin{array}{l}\text { Energy-intensive } \\
\text { manufacturing }\end{array}$ & \\
\hline & Food & $\begin{array}{l}\text { Food, beverage, and tobacco product } \\
\text { manufacturing }\end{array}$ \\
\hline & Pulp and paper & $\begin{array}{l}\text { Paper manufacturing, printing, and related } \\
\text { support activities }\end{array}$ \\
\hline & Basic chemicals & $\begin{array}{l}\text { Inorganic chemicals, organic chemicals } \\
\text { (e.g., ethylene-propylene), resins, and } \\
\text { agricultural chemicals; includes chemical } \\
\text { feedstocks }\end{array}$ \\
\hline & Refining & $\begin{array}{l}\text { Petroleum refineries and coal products } \\
\text { manufacturing, including coal and natural } \\
\text { gas used as feedstocks }\end{array}$ \\
\hline & Iron and steel & $\begin{array}{l}\text { Iron and steel manufacturing, including } \\
\text { coke ovens }\end{array}$ \\
\hline & Non-ferrous metals & $\begin{array}{l}\text { Primarily aluminium and other nonferrous } \\
\text { metals, such as copper, zinc, and tin }\end{array}$ \\
\hline & Nonmetallic minerals & $\begin{array}{l}\text { Primarily cement and other nonmetallic } \\
\text { minerals, such as glass, lime, gypsum, and } \\
\text { clay products }\end{array}$ \\
\hline
\end{tabular}

2. Non-energy-intensive manufacturing Other chemicals

Pharmaceuticals (medicinal and botanical), paint and coatings, adhesives, detergents, and other miscellaneous chemical products, including chemical feedstocks

Other industrials All other industrial manufacturing, including metal-based durables (fabricated metal products, machinery, computer and electronic products, transportation equipment, and electrical equipment)

3. Non-manufacturing

Agriculture, forestry, Agriculture, forestry, and fishing fishing

Mining

Coal mining, oil, and natural gas extraction, and mining of metallic and nonmetallic minerals

Construction Construction of buildings (residential and commercial), heavy and civil engineering construction, industrial construction, and speciality trade contractors

and reducing the current demand for transport, however, this may be difficult in the countries where the population is fast growing; (ii) shifting demand to more efficient modes of transport; and (iii) improving the used vehicles and fuels. Efforts for energy efficiency can be achieved if it starts from individual, institutional, country to global level.

Residential uses of energy

The energy uses in the residential areas are considered as the most basic uses of energy. They include watching television, listening to music on the radio, cooking food, heating water, washing clothes, heating, and lighting the home, taking a shower, working from home on laptops or computers, and operating appliances. Residential uses of energy account for almost 25\% of total global energy consumption (Pablo-Romero et al., 2017). It is believed that the increase of residential energy demand depends on the income levels of the households. Also, the use of energy in an efficient manner depends on the 
households' behaviours. As it has been discussed in section 2 , individual altitudes, norms, culture, habits, and experiences determine the use of energy at household levels.

Commercial uses of energy

Energy uses in the commercial sector differs from that one used in industries. Commercial energy use is highly connected to population growth. Moreover, it is driven by electrical, cooling or heating of buildings and other structures (Jordan, 2014). It also includes traffic lights, water and sewer systems, and power used by companies and businesses throughout our cities for computers, fax machines, workstations, and photocopiers. The demand for energy in the commercial sector is indicated by the number of buildings, the number of workers in a building and operating hours in the buildings (Ponniran et al., 2012).

\section{Energy Efficiency and Energy Security}

Energy access is considered a key pillar for human wellbeing, economic development, and poverty alleviation. However, sufficient and efficient access to all is an alarming challenge for global development. This is triggering the achievement of sustainable development goals. Thus, every country is trying to secure energy through energy consumption efficiency. According to the British Geological Survey (BGS, 2020), energy efficiency "means using less energy to provide the same level of energy". It is among the methods to reduce human greenhouse gas emissions. Energy efficiency is sometimes known as efficient energy use (Umachagi et al., 2015). Currently, making homes, vehicles, and businesses more energy efficient is seen as a largely untapped solution to addressing global warming, energy security, and fossil fuel depletion. Thus, more efforts are required to ensure energy efficiency at the individual to global levels. Energy efficiency minimizes the amount and cost of energy imports and the likelihood of supply interruptions. It ensures both short and long-term energy security in a cost-effective way (IEA, 2019).

According to the International Energy Association (IEA, 2020), energy security is all about reliable and affordable access to all fuels and energy sources. Energy security indicates the presence of constant energy supply in the country (Selvakkumaran \& Limmeechokchai, 2013). It indicates the reliable supply of energy and access to energy resources and fuel in the required quantity and quality at reasonable prices. This term still considers in detail the availability, affordability, reliability, efficient, environmental benignant, properly governed and socioeconomically acceptable energy services (Pasqualetti \& Benjamin, 2012). Energy security is a necessary benefit of energy efficiency measures (Sauter \& Volkery, 2013).

\section{ENERGY USE IS STRONGLY RELATED TO ECONOMIC GROWTH AND POVERTY ALLEVIATION}

Energy has a crucial role to play in a global development context. The potential for energy to improve living standards, whether through the freeing of time from household chores (for example, washing clothes or cooking); increased productivity; improved healthcare and education services; or digital connections to local, regional and global networks

The link between energy consumption and economic growth has been a topic of wide discussion. A large number of studies have attempted to derive the causal relationship between energy consumption and economic growth, however, no clear consensus has emerged (Chontanawat et al., 2008).

This can be partly attributed to the fact that the link between energy and prosperity is not always unidirectional. Gaining access to electricity and other energy sources may provide an initial increase in GDP, but having higher GDP may, in turn, drive higher energy consumption. Additionally, progress in development outcomes can be complex: several parameters may be improving at the same time. If, for example, energy access and consumption, nutrition, education, health, and sanitation are all improving simultaneously (and having complex relationships with one another), it can be hard to directly attribute the improvement in living standards back to a single parameter (Ritchie \& Roser, 2018).

Chontanawat et al. (2008) carried out a systematic study across 100 countries to try to reach a common consensus on the energy-GDP link. Likewise, Akinlo (2008) did similarly across 11 Sub-Sahara African countries to define a common relationship. Neither found a causal relationship which was true in all contexts. For some countries, the relationship was unidirectional (energy consumption was a direct and long-term driver of economic growth), others are bidirectional; some are integrated with other factors, and for some, there was no clear link between the two. Nonetheless, for most countries, there is an important relationship between energy and prosperity. However, the exact dynamics of each is complex and context-dependent.

\section{THE ENERGY SITUATION IN TANZANIA}

Tanzania has abundant and diverse indigenous energy resources which are yet to be fully exploited. The sources include; wood fuel and other biomass fuels, hydropower, natural gas, coal, uranium, wind, geothermal and solar (Bishoge et al., 2018). Tanzania's energy supply depends mainly on biomass. Since $85-$ $90 \%$ of the population is not connected to the electricity grid, the overwhelming majority of households use wood and charcoal for cooking. As a total, biomass makes up close to $90 \%$ of the total primary energy consumption in Tanzania. Unfortunately, this leads to the deforestation of $100,000 \mathrm{~h}$ per year, of which only about a quarter is reforested. Other energy sources are petroleum, which makes up $7.8 \%$ of total primary energy consumption, natural gas $(2.4 \%)$, hydropower $(1.2 \%)$ and coal/peat $(0.3 \%)$. About 6.6 per cent of primary energy needs to be imported, primarily from Uganda (8 MW) and Zambia (5 MW) (Msyani, 2013).

\section{THE IMPACT OF THE ENERGY RESOURCES TO THE ENVIRONMENT}

The increased use of energy has stimulated climate change problems globally. There is a gradual increase in greenhouse 
gases emissions from various sources of energy. The primary greenhouse gases in earth's atmosphere are carbon dioxide $\left(\mathrm{CO}_{2}\right)$, methane $\left(\mathrm{CH}_{4}\right)$, and water vapour $\left(\mathrm{H}_{2} \mathrm{O}\right)$. Others include sulfur dioxide $\left(\mathrm{SO}_{2}\right)$, chlorofluorocarbons (CFCs), ozone $\left(\mathrm{O}_{3}\right)$, and Nitrous oxide $\left(\mathrm{N}_{2} \mathrm{O}\right)$ (Dincer, 1999). The increase of these gases in the atmosphere leads to global climate change, stratospheric ozone layer depletion, and acid rain. The emission of $\mathrm{CO}_{2}$ gases is considered as major greenhouse gas globally. There is an emission of over 36 million tonnes of $\mathrm{CO}_{2}$ per year globally, and this continues to increase (Ritchie \& Roser, 2019). Currently, China is the world's large $\mathrm{CO}_{2}$ contributor accounting for over one-quarter $(28 \%)$ of the global emissions followed by the United States (15\%), European Union (10\%), India (7\%), and Russia (5\%) (Bishoge et al., 2019). However, the United States has contributed much of the global $\mathrm{CO}_{2}$ emissions with $25 \%$ of cumulative emissions, followed by the European Union (22\%), China (13\%), Russia (6\%), and Japan (4\%) (Ritchie, 2019). $\mathrm{CO}_{2}$ emissions differ from developed and developing countries. The world's poorest countries contribute less than $1 \%$ of the global emissions but they are most vulnerable to climate change impacts (Ritchie \& Roser, 2019). The rate of the impacts of various energy sources on the environment is presented in Table 3.

\section{ATTAINING SUSTAINABLE ENERGY AND ENVIRONMENT}

\section{Energy savings and practices to best energy use}

The attempts to address energy efficiency should focus on the technology, architecture of the buildings, and behaviour of the energy users (Hussaini, 2016). The improvement of technology or process is a primary way of achieving efficient energy use.

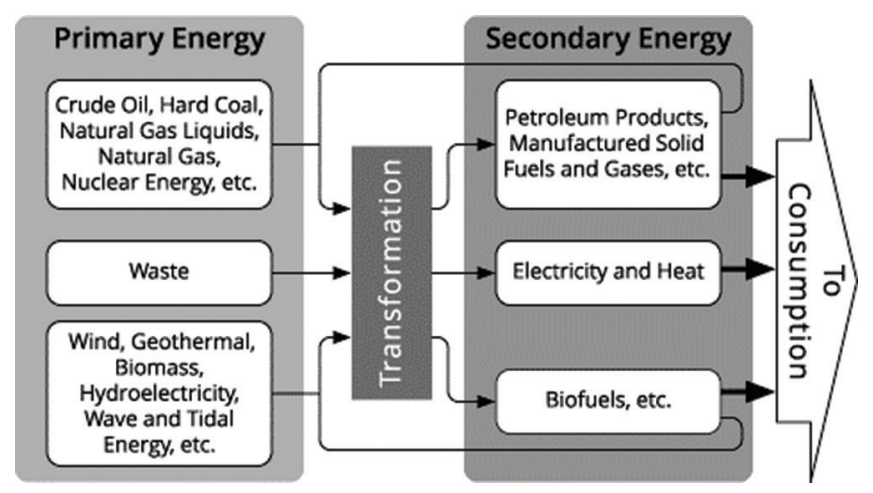

Figure 2: Transformation scheme of primary energy to secondary energy (The University of Texas, 2020)
Technological advances increase energy efficiency because these improvements lower the amount of energy a product uses low energy while performing at the same level. On the other hand, technological advancement is associated with affluence (economic growth) which increases energy demand. An increase in transportation is positively linked to energy consumption.

The advances in architectural of the building is another way where energy efficiency can be achieved. For instance, if a house is insulated, less energy is used in heating and cooling to achieve a satisfactory temperature. Also installing fluorescent light bulbs or skylights instead of incandescent light bulbs may help to attain the same level of illumination is one of the primary means for more efficient use of energy. Energy-efficient buildings, industrial processes, and transportation could reduce the world's energy needs by one third in 2050, and help control global emissions of greenhouse gases. Moreover, energy users' behaviours such as habits, attitudes, awareness, environmental norms, and affection are very vital ways toward energy efficiency. According to Trotta (2018), energy-saving behaviours can be defined "as the daily and habitual practices of households that focus on specific reductions in energy use".

\section{Use of Technologies to Reduce the Pollutant Emissions in the Atmosphere}

Air pollution levels have been increasing in recent years. Air emissions have many adverse environmental effects such as global warming, ozone depletion, acidification, or eutrophication of natural ecosystems and biodiversity of freshwater bodies. On the other hand, long-term exposure to air pollution has a serious impact on human health affecting the lungs and the respiratory system. The principal pollutants of air pollution are carbon dioxide, nitrate, sulphate, carbon monoxide, other organic and inorganic gases, as well as particulate matters. Air pollutants can be reduced by using a wide range of air pollution control devices to prevent their adverse effects on the environment and human health.

Many technological applications serve this purpose. Incinerators, gravitational settling chambers, electrostatic precipitators, cyclone separators, selective catalytic reduction systems, fabric filters, biofilters, and scrubbers are the main air pollution prevention technologies. The decision of the suitable control devices depends on the type of air pollutants and condition at the sources. If the amount of pollutants emitted to the atmosphere is decreased, the atmospheric concentrations of the

Table 3: The comparison of environmental impacts among the energy sources

\begin{tabular}{|c|c|c|c|c|c|c|}
\hline \multirow[t]{2}{*}{ Impact category } & \multicolumn{6}{|c|}{ Energy source } \\
\hline & Biomass & Coal & Nuclear & Natural gas & Solar & Wind \\
\hline Planning and cost risk & Moderated & High & High & Moderated & Low & Low \\
\hline Climate change & Moderated & High & Low & High & Low & Low \\
\hline Air pollution & Moderated & High & Low & Moderated & Low & Low \\
\hline Land & Moderated & High & High & Moderated & Moderated & Moderated \\
\hline Water & Moderated & High & High & High & Low & Low \\
\hline Other impacts (Noise/Visual) & Moderated & Moderated & High & Moderated & Low & Moderated \\
\hline
\end{tabular}

Source: SolarFeeds Editorial Team (2012) 
pollutants will also decrease. As a result, exposure to air pollution declines and adverse effects of air pollution on the environment and human health are taken under control.

\section{Investment in renewable technologies}

Shifting our energy systems away from fossil fuels towards renewable technologies will require a significant financial investment. However, currently, renewable energy (RE) sector is challenged with various obstacles such as financial and human resources, insufficient institutional and regulatory framework and inadequate or poor awareness of RE technologies among the local communities.

Thus, there is a need for cooperation between governments and other energy stakeholders in addressing and solving these challenges. More efforts are needed to invest in RE technologies to achieve SDGs by 2030. Moreover, there is the need for renewed political will and commitment of domestic and foreign funding agencies to achieve RE initiatives for addressing energy access poverty.

\section{CONCLUSION AND REMARKS}

Energy and the environment have always been and will continue to be closely linked. All energy is, at the bottom, either derived or captured from the environment around us. Once used, it is eventually returned to the environment as a harmless byproduct or, more often than not, as harmful emissions or waste. As energy usage has increased around the world, so too have the stresses this usage imposes on the environment intensified. Globalization has accelerated the pace of these developments and ensured that the actions of one country are felt more acutely in many others.

The relationship between energy and the environment is largely defined by the economic concept of externalities. An externality is a hidden or indirect cost associated with an activity or the transaction of a good or service. Because the burden of this cost often falls on outside bystanders who had no part in the activity or transaction, it is not reflected in the market price encountered by the buyer or seller. Thus, for example, the price an individual pays for a litre of fuels such as petroleum does not reflect the full costs that carbon emissions from the burning of that gasoline impose on the broader community (such as global warming and adverse health effects).

Beyond the market price set by supply and demand is a broader notion of the cost that takes into account the "full social costs" paid by those directly involved in a transaction as well as any external parties affected by it. This full social cost is particularly relevant when public goods such as clean air and clean water are concerned. Conventional reasoning holds that because a communal resource belongs to everyone, in theory, it belongs to no one in practice. The benefits of an action that exploits the environment, like burning coal or driving a car, are highly concentrated among those directly involved, for example, the energy company or the driver. But the real-life costs of such actions are widely distributed among the population at large, e.g. affecting people in neighbouring countries who have to deal with acid rain or pedestrians who are forced to breathe in a car's exhaust fumes. This distribution means that no individual feels responsible for the full social costs of his or her activities.

Governments can step in to help bring the market cost of an activity in line with the full social cost. They often do this by assessing the difference between the two and levying a tax that artificially raises the market cost. In economic terms, this is known as "internalizing the externality." As will become clear throughout this section, externalities and the ways governments handle them are in many respects the central threads connecting energy and the environment.

More generally, it must always be remembered that the competing needs of energy users and environmental protection must be carefully balanced if economic growth is to be sustainable as well as robust.

\section{ACKNOWLEDGEMENTS}

The author thanks African Union and Pan African University Life and Earth Sciences Institute for the award of $\mathrm{PhD}$ admission; and the National Institute for Medical Research, Tanzania for granting study leave. Moreover, the author thanks Prof. Chris O. Ikporukpo, Prof. A.S. Gbadegesin and Ms Witness Gerald Mushi for their support in writing this paper.

\section{REFERENCES}

Akinlo, A. E. (2008). “Energy Consumption and Economic Growth: Evidence from 11 Sub-Sahara African Countries." Energy Economics 30(5), 2391-2400. https://doi.org/10.1016/.eneco.2008.01.008

Alley, R. B., Blumsack, S., Bice, D., \& Feineman, M. (2020). Global Energy Sources, Earth 104: Energy and the Environment (Development). https://www.e-education.psu.edu/earth104/node/1345

BGS. (2020). "What Is Energy Efficiency?" British Geological Survey. https://www.bgs.ac.uk/discoveringGeology/climateChange/CCS/ whatlsEnergyEfficiency.html

Bishoge, O. K., Huang, X., Zhang, L., \& Ma, H. (2019). The Adaptation of Waste-to-Energy Technologies: Towards the Conversion of Municipal Solid Waste into a Renewable Energy Resource. Environmental Reviews, 27(4), 435-446. https://doi.org/10.1139/er-2018-0061

Bishoge, O. K., Zhang, L., \& Mushi, G. (2018). The Potential Renewable Energy for Sustainable Development in Tanzania: A Review. Clean Technologies, 1(1), 70-88. https://doi.org/10.3390/ cleantechnol1010006

BP. (2019). BP Statistical Review of World Energy Statistical Review of World, 68 $8^{\text {th }}$ Edition. The Editor BP Statistical Review of World Energy, 1-69. https://www.bp.com/content/dam/bp/business-sites/en/global/ corporate/pdfs/energy-economics/statistical-review/bp-stats-review2019-full-report.pdf

Chontanawat, J., Hunt, L. C., \& Pierse, R. (2008). Does Energy Consumption Cause Economic Growth?: Evidence from a Systematic Study of over 100 Countries. Journal of Policy Modeling, 30(2), 209-220. https:// doi.org/10.1016/j.jpolmod.2006.10.003

D'Odorico, P., Davis, K. F., Rosa, L., Carr, J. A., Chiarelli, D., Dell'Angelo, J., Gephart, J., MacDonald, G. K., Seekell, D. A., Suweis, S., \& Cristina, M. (2018). The Global Food-Energy-Water Nexus. Reviews of Geophysics, 56(3), 456-531. https://doi.org/10.1029/2017RG000591

Dincer, I. (1999). Environmental Impacts of Energy. Energy Policy, 27(14), 845-54.

Hanania, J., Boechler, E., Suarez, L. V., \& Donev, J. (2020a). Industrial Energy Use - Energy Education. https://energyeducation.ca/encyclopedia/ Industrial_energy_use 
Hanania, J., Boechler, E., Stenhouse, K., Suarez, L. V., \& Donev, J. (2020b). Transportation Energy Use - Energy Education. https:// energyeducation.ca/encyclopedia/Transportation_energy_use

Hussaini, I. U. (2016). Households' Energy Efficiency Practices in a Bereft Power Supply Economy of Nigeria, IntechOpen, 1-18. https://doi. org/10.5772/intechopen.81408

IEA. (2019). Energy Security: Multiple Benefits of Energy Efficiency-Analysis. https://www.iea.org/reports/multiple-benefits-of-energy-efficiency/ energy-security

IEA. (2020). Energy Security - Topics. https://www.iea.org/topics/energysecurity

Jordan, P. G. (2014). Global Markets. In Solar Energy Markets, 127-133.

Kutani, I. (2017). Addressing Energy Efficiency in the Transport Sector through Traffic Improvement.

Msyani, C. M. (2013). Current Status of Energy Sector in Tanzania Executive Exchange on Developing an Ancillary Service Market Usea Washington Dc 25 Th February - 2 Nd March 2013. https://www. usea.org/sites/default/files/event-/Tanzania Power Sector.pdf

National Research Council. (2010). Energy Efficiency in Transportation. In Real Prospects for Energy Efficiency in the United States, Washington, DC: The National Academies Press, 121-130.

Nelson, S. A. (2015). Energy Resources. https://www.tulane.edu/ sanelson/ eens1110/energy.htm

Pablo-Romero, M. P., Pozo-Barajas, R., \& Yñiguez, R. (2017). Global Changes in Residential Energy Consumption. Energy Policy, 101, 342-352. https://doi.org/10.1016/j.enpol.2016.10.032

Pasqualetti, M. J., \& Benjamin, K. S. (2012). The Importance of Scale to Energy Security. Journal of Integrative Environmental Sciences, 9(3), 167-80. https://doi.org/10.1080/1943815X.2012.691520

Ponniran, A., Mamat, N. A., \& Joret, A. (2012). “Electricity Profile Study for Domestic and Commercial Sectors. International Journal of Integrated Engineering, 4(3), 8-12. http://penerbit.uthm.edu.my/ojs/index.php/ ijie/article/viewFile/616/402

Ritchie, H. (2019). Our World in Data. Who Has Contributed Most to Global CO2 Emissions?. https://ourworldindata.org/contributedmost-global-co2

Ritchie, H., \& Roser, M. (2018). Our World in Data. Energy. https:// ourworldindata.org/energy

Ritchie, H., \& Roser, M. (2019). Our World in Data. CO ${ }_{2}$ and Greenhouse Gas Emissions. https://ourworldindata.org/co2-and-other-greenhousegas-emissions

Sauar, E. (2018). Primary Energy - and How to Count It.
Sauter, R., \& Volkery. A. (2013). Review of Costs and Benefits of Energy Savings, A Report by the Institute for European Environmental Policy (IEEP) for the Coalition of Energy Savings. Task 1 Report. Brussels. Brussels.

Selvakkumaran, S., \& Limmeechokchai, B. (2013). Energy Security and CoBenefits of Energy Efficiency Improvement in Three Asian Countries. Renewable and Sustainable Energy Reviews, 20, 491-503. https:// doi.org/10.1016/j.rser.2012.12.004

Simpson, G. B., \& Jewitt, G. P.W. (2019). The Development of the WaterEnergy-Food Nexus as a Framework for Achieving Resource Security: A Review. Frontiers in Environmental Science, 7, 1-9.

SolarFeeds Editorial Team. (2012). What Power Generation Is Doing to the Environment: SolarFeeds Marketplace. https://solarfeeds.com/ what-power-generation-is-doing-to-the-environment

The University of Texas. (2020). Energy Resources: Primary vs. Secondary - Watt Watchers of Texas. https://www.watt-watchers. com/activity/energy-resources-primary-vs-secondary

The World Bank. (2018). Access to Energy Is at the Heart of Development. https://www.worldbank.org/en/news/feature/2018/04/18/accessenergy-sustainable-development-goal-7

Trotta, G. (2018). Factors Affecting Energy-Saving Behaviours and Energy Efficiency Investments in British Households. Energy Policy, 114, 529-39. https://doi.org/10.1016/j.enpol.2017.12.042

EIA. (2013). Future World Energy Demand Driven by Trends in Developing Countries - Today in Energy. U.S. Energy Information Administration. https://www.eia.gov/todayinenergy/detail.php?id=14011

EIA. (2016). 0484 International Energy Outlook and Projections International Energy Outlook U.S. Energy Information Administration.

Umachagi, P. K., Jangali S. G., \& Kotturshettar, B. B. (2015). Study of Energy Consumption in Residential and Commercial Sector of Hubli City. IJIRST -International Journal for Innovative Research in Science \& Technology, 1(11), 83-91.

Xavier, R., Komendantova, N., Jarbandhan, V., \& Nel, D. (2017). Participatory Governance in the Transformation of the South African Energy Sector: Critical Success Factors for Environmental Leadership. Journal of Cleaner Production, 154, 621-32. https://doi.org/10.1016/j. jclepro.2017.03.146

Zaharia, A., Diaconeasa, A. C., Brad, L., Lădaru, G., \& loanăș, C. (2019). Factors Influencing Energy Consumption in the Context of Sustainable Development. Sustainability (Switzerland), 11(15), 4147 https://doi.org/10.3390/su11154147 